\title{
Evaluating text-based information on the World Wide Web
}

Citation for published version (APA):

Wopereis, I. G. J. H., \& van Merrienboer, J. J. G. (2011). Evaluating text-based information on the World Wide Web. Learning and Instruction, 21(2), 232-237. https://doi.org/10.1016/j.learninstruc.2010.02.003

Document status and date:

Published: 01/04/2011

DOI:

10.1016/j.learninstruc.2010.02.003

Document Version:

Publisher's PDF, also known as Version of record

Document license:

Taverne

Please check the document version of this publication:

- A submitted manuscript is the version of the article upon submission and before peer-review. There can be important differences between the submitted version and the official published version of record.

People interested in the research are advised to contact the author for the final version of the publication, or visit the DOI to the publisher's website.

- The final author version and the galley proof are versions of the publication after peer review.

- The final published version features the final layout of the paper including the volume, issue and page numbers.

Link to publication

\footnotetext{
General rights rights.

- You may freely distribute the URL identifying the publication in the public portal. please follow below link for the End User Agreement:

www.umlib.nl/taverne-license

Take down policy

If you believe that this document breaches copyright please contact us at:

repository@maastrichtuniversity.nl

providing details and we will investigate your claim.
}

Copyright and moral rights for the publications made accessible in the public portal are retained by the authors and/or other copyright owners and it is a condition of accessing publications that users recognise and abide by the legal requirements associated with these

- Users may download and print one copy of any publication from the public portal for the purpose of private study or research.

- You may not further distribute the material or use it for any profit-making activity or commercial gain

If the publication is distributed under the terms of Article $25 \mathrm{fa}$ of the Dutch Copyright Act, indicated by the "Taverne" license above, 


\title{
Evaluating text-based information on the World Wide Web
}

\author{
Iwan G.J.H. Wopereis $^{a, *}$, Jeroen J.G. van Merriënboer ${ }^{\text {a,b }}$ \\ ${ }^{a}$ Centre for Learning Sciences and Technologies, Open University of the Netherlands, PO Box 2960, 6401 DL Heerlen, The Netherlands \\ ${ }^{\mathrm{b}}$ Department of Educational Development and Research and School of Health Professions Education, Maastricht University,
} PO Box 616, 6200 MD Maastricht, The Netherlands

\begin{abstract}
This special section contributes to an inclusive cognitive model of information problem solving (IPS) activity, touches briefly IPS learning, and brings to the notice methodological pitfalls related to uncovering IPS processes. Instead of focusing on the IPS process as a whole, the contributing articles turn their attention to what is regarded the heart of IPS, namely the evaluation of information. In this commentary we reflect on theoretical, methodological, and instructional design issues. Results are commented upon and future research is addressed. A vignette is presented to illustrate the aforementioned issues.
\end{abstract}

(C) 2010 Elsevier Ltd. All rights reserved.

Keywords: Information problem solving; Evaluation; Text; World Wide Web

\section{Introduction}

Suppose you live in a country where swine influenza is spreading fast. And suppose the authorities just decided to recommend immediate vaccination for children aged six months through five years. You have a child six months old who is in perfectly good health. Do you take the authorities' advice and decide to vaccinate, or do you disregard this advice and trust information on negative side effects and subsequent health risks? In order to make a balanced decision you would probably try to find a multiple set of reliable information sources on swine flu vaccination and health risks. And, provided you have an Internet connection, you would most likely search the World Wide Web to find this set of sources (Lemire, Paré, Sicotte, \& Harvey, 2008). You would probably open an Internet search engine and perform a keyword search using keywords like 'swine flu' and 'vaccination'. Fig. 1 is an example of a search engine results page (SERP) that might be presented to you (retrieved December 9, 2009).

\footnotetext{
* Corresponding author.

E-mail address: iwan.wopereis@ou.nl (I.G.J.H. Wopereis).
}

You would presumably iteratively evaluate information presented by the SERP, select sources from the SERP, and evaluate the information presented by the sources, until you think you have enough information to make your decision. Prior knowledge regarding the topic (e.g., vaccination and flu) and Web-based publishing (e.g., everyone with an Internet connection can provide information on the Web) would most likely affect your selection of information. Further, your belief how medical knowledge comes about could be decisive when you select sources. Most likely your Web search will provide you information that can help you make a decision. However, it is also possible that a proper decision is beyond reach because you are "forced" to end the Web-based search due to time constraints or frustration as a result of getting "lost" in cyberspace and/or you are not able to find or infer a univocal answer.

The vignette presented above covers a process frequently referred to as information problem solving (IPS; Brand-Gruwel, Wopereis, \& Vermetten, 2005; Eisenberg \& Berkowitz, 1990; Moore, 1995). This process includes activities such as searching, scanning, processing, organizing, and (if necessary) presenting information-activities which are typically performed in an iterative fashion to fulfill a (pre-)defined information need. 


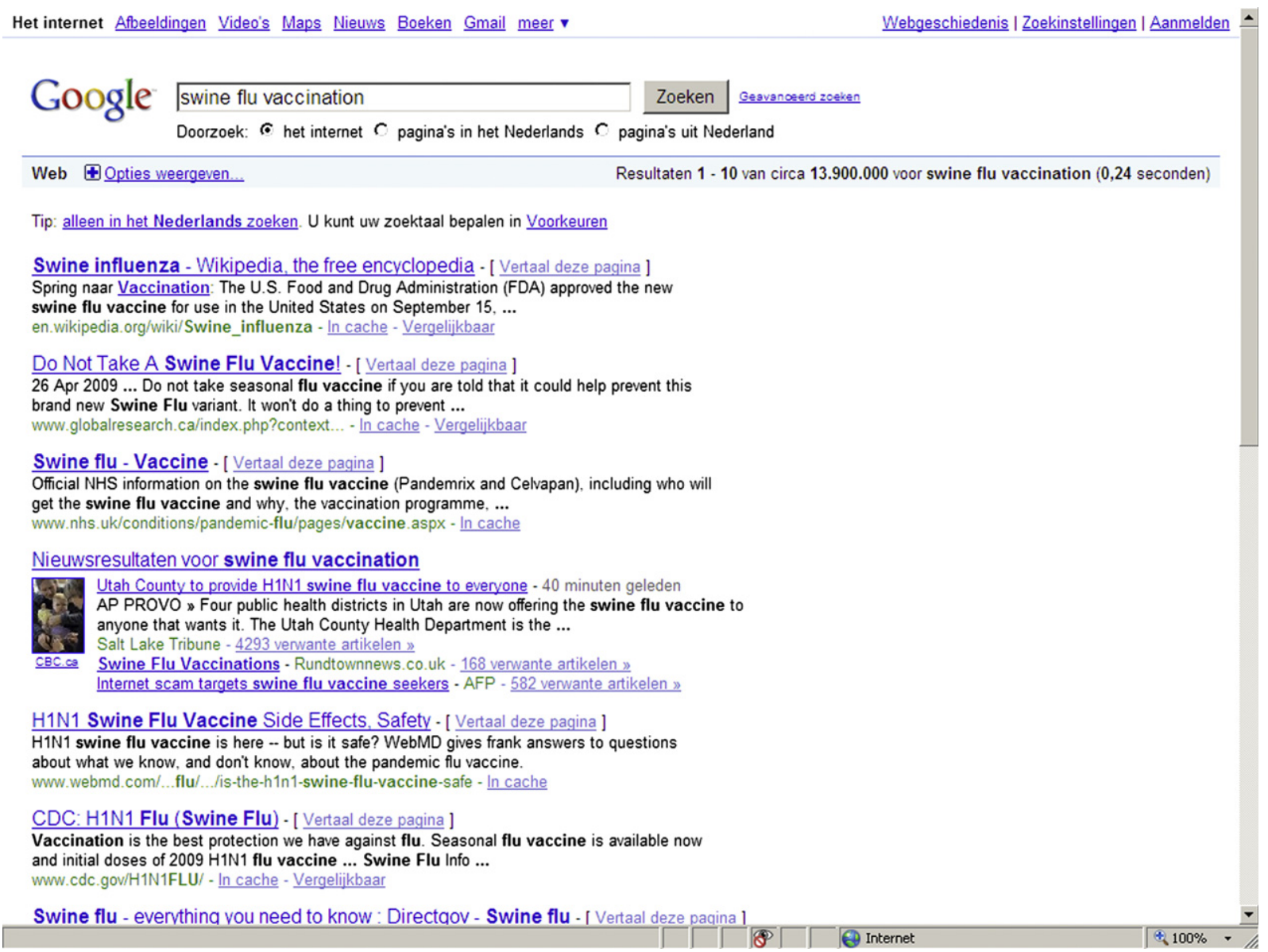

Fig. 1. Search engine results page for keyword search.

With the advent of the Internet in education (Hill \& Hannafin, 1997), IPS gained special attention in educational research. This resulted in updated (descriptive) IPS models (BrandGruwel, Wopereis, \& Walraven, 2009; Hill, 1999) and, more interestingly, better understanding of effective instructional support for learning IPS skills (Brand-Gruwel \& Gerjets, 2008; Graesser et al., 2007; Stadtler \& Bromme, 2007). However, as Lazonder and Rouet (2008) argue, some aspects of the IPS (learning) process, like metacognitive mediation and collaborative search, are relatively underexposed in (educational) IPS research. According to Rouet, Ros, Goumi, Macedo-Rouet, and Dinet (2011), an even more serious concern is the absence of a comprehensive model of the cognitive processes involved in IPS activity. A statement which is by no means out of the ordinary, since the Internet (and corresponding usability research) is relatively young and above all evolving at a great pace (Leiner et al., 2009).

The present special section contributes to an inclusive cognitive model of IPS activity, touches briefly IPS learning, and brings to notice methodological pitfalls related to uncovering IPS processes. Instead of focusing on the IPS process as a whole, the contributing articles turn their attention to what is regarded the heart of IPS, namely the evaluation of information (Lazonder \& Rouet, 2008). Rouet et al. (2011) scrutinized students' source selection strategies in simulated
SERPs. Bråten, Strøms $\varnothing$, and Salmerón (2011) examined how readers judge the trustworthiness of authentic source materials on a complex topic (i.e., climate change). Kienhues, Stadtler, and Bromme (2011) investigated whether and how conflicting and consistent Web-based information influences epistemic beliefs and decision making (cf. the aforementioned vignette). Finally, Gerjets, Kammerer, and Werner (2011) researched methods used to uncover evaluation processes during IPS. Table 1 presents an overview of the four papers in this special section. In this commentary we will reflect on theoretical, methodological, and instructional design issues. Before reflecting, we will analyze the contributions in light of the central topic of this special section (evaluation) and the dimensions of IPS activity (cf. Lazonder \& Rouet, 2008).

\section{Evaluating text-based information on the web}

Gerjets et al. (2011) distinguish three different types of evaluation processes when performing a Web-based IPS task, that is, the evaluation of (a) SERPs, (b) Web pages, and (c) document collections. This classification matches the three IPS evaluation skills described by Brand-Gruwel et al. (2005), namely "judging search results", "judging scanned information", and "judging processed information". Interestingly, the four contributing studies all address different (combinations 
Table 1

A selection of focal points of the contributing articles.

\begin{tabular}{|c|c|c|c|c|}
\hline Study & Participants & Research focus & Task focus & Criteria focus \\
\hline $\begin{array}{l}\text { Rouet et al. } \\
\qquad(2011)\end{array}$ & $\begin{array}{l}\text { Primary and secondary school } \\
\text { students (Experiment } 1: N=174 \text {; } \\
\text { Experiment } 2: N=88 \text { ) }\end{array}$ & Menu selection strategies & Evaluation of SERPs & $\begin{array}{l}\text { Relevance, i.e., surface versus } \\
\text { deep cues }\end{array}$ \\
\hline $\begin{array}{l}\text { Bråten et al. } \\
\text { (2011) }\end{array}$ & University students $(N=128)$ & $\begin{array}{l}\text { Judgment of trustworthiness of } \\
\text { information sources }\end{array}$ & $\begin{array}{l}\text { Evaluation of information } \\
\text { sources }\end{array}$ & Trustworthiness \\
\hline $\begin{array}{l}\text { Kienhues et al. } \\
\text { (2011) }\end{array}$ & University students $(N=100)$ & $\begin{array}{l}\text { Effect of conflicting and consistent } \\
\text { information on epistemic beliefs } \\
\text { and decision making }\end{array}$ & $\begin{array}{l}\text { Evaluation of information } \\
\text { sources }\end{array}$ & $\begin{array}{l}\text { Topic-specific and discipline-related } \\
\text { epistemic beliefs }\end{array}$ \\
\hline $\begin{array}{l}\text { Gerjets et al. } \\
\quad(2011)\end{array}$ & University students $(N=30)$ & $\begin{array}{l}\text { Multi-method measurement of } \\
\text { evaluation criteria }\end{array}$ & $\begin{array}{l}\text { Evaluation of SERPs and } \\
\text { information sources }\end{array}$ & $\begin{array}{l}\text { Relevance, i.e., topic-related and } \\
\text { quality-related criteria }\end{array}$ \\
\hline
\end{tabular}

of) evaluation types (see Table 1). The experiments of Rouet et al. (2011) focus on evaluating a (simulated) SERP. Gerjets et al. (2011) zoom in on the evaluation of (simulated) SERPs and Web pages, and also touch on the evaluation of document collections. Kienhues et al. (2011) focus on the evaluation of (authentic) Web pages and document collections. Finally, Bråten et al. (2011) zoom in on the evaluation of different (authentic) document types, which could have been published on the Internet (but actually were presented off-line to the students during the experiment). In sum, all relevant types of evaluation processes are covered in this special section.

Beside different types of evaluation processes, the contributing articles address different evaluation frameworks to describe and measure the evaluation behavior of the participants in their studies. Bråten et al. (2011) focus on evaluating (judging) the trustworthiness of texts when reading multiple documents on a particular issue. To measure the trustworthiness of a text, the participating students rated whether they were influenced in their judgment by (a) the author of the text, (b) the text publisher, (c) the type of text, (d) the content of the text, (e) their own opinion about the topic at issue, and (f) publishing date of the text. Gerjets et al. (2011) based their coding scheme to analyze concurrent verbal protocols focusing evaluation behavior on information science research. This coding scheme consisted of two topic-related evaluation criteria (topicality and scope) and three quality-related criteria (credibility, up-todateness, and design). Rouet et al. (2011) researched students' use of surface cues (typographical cues, like underlined and/or capitalized keywords) and deep cues (semantic information in title, URL address, and excerpt) for selecting sources from SERPs. Although evaluation of information was central to the experimental tasks of Kienhues et al.'s (2011) study this was not measured in depth, since the authors were interested in the effect of consulting a set of conflicting information sources versus a set of consistent information sources on epistemic beliefs and decision making; it was sufficient for them to distinguish information consistency. However, due to the "time-on-task" constraint in the experimental task (30 min for consulting 15 sources, that is, $120 \mathrm{~s}$ for scanning each source) it is likely that participants consulted a selection of sources available. This might for instance have affected the results of the decision making task, a possibility which is recognized by Kienhues et al.
(2011) Therefore it would be of interest for future research to analyze task performance in depth to elicit source selection. Cued-retrospective reporting could be an option (Van Gog, Paas, Van Merriënboer, \& Witte, 2005). In sum, the studies described in this special section used different frameworks for describing and measuring evaluation behavior. This is partly due to the focus on different types of evaluation processes. Nevertheless, a unified framework for assessing Web-based information is important for describing all facets of information evaluation (see, e.g., Hilligoss \& Rieh, 2008). This framework should also address task type or task complexity. The vignette presented in the introduction of the present commentary, for instance, presents a problem which has to be tackled within time limits. Time constraints, especially apparent in emergency management tasks, will most likely influence evaluation behavior and should, therefore, regarded a task complexity factor.

\section{Cognitive dimensions of IPS activity}

According to Lazonder and Rouet (2008) a description of IPS in terms of cognitive dimensions helps to build up a comprehensive cognitive IPS model. They distinguish three dimensions: (a) individual variables like prior knowledge and personal epistemology, (b) contextual variables such as task conditions (i.e., time constraints; individual versus collaborative, etc.), and (c) resource variables like amount and type of information available. In the present commentary we will elaborate on the first dimension. Individual variables include the individual's prior knowledge, general skills, and personal epistemology. An extension of the aforementioned vignette illustrates that these variables affect the quality of the IPS process. Suppose the parent mentioned in the vignette is a general practitioner. Prior knowledge on spreading diseases, vaccination programs, and accompanying health risks will probably help him/her to select (additional) information from the Web to validate initial ideas on what to decide. In case the parent is a sculptor, reliable sources with up-to-date information have to be found to compensate the lack of a medical knowledge base. In case a 5th-grade student is presented with this vaccination problem, it is most likely that his/her decision to vaccinate is based on information retrieved from the first comprehensible document selected in the SERP. Naïve knowledge regarding the trustworthiness of Web-based 
information ("everything on the Web is true") and an absolutist stance of knowledge will most likely determine his/her document and information selection.

As Bråten et al. (2011) state there is ample evidence that experts outperform novices on IPS tasks. This is because experts possess a large knowledge base and advanced general skills (like reading skills) that help them to free up working memory capacity for the execution of all sorts of IPS processes (including the evaluation of SERPs and sources). Further, since experts have normally a sophisticated view on knowledge and knowing, this will help them to assess information more accurately. Bråten et al. (2011) found that also novices in a certain domain who are relatively knowledgeable about a domain-specific topic, evaluate the information better. The relatively knowledgeable novices mistrusted less trustworthy sources more frequently and were less influenced by superficial text features than the "unknowledgeable" novices. Or, as the researchers put it eloquently, "the knowledge base of the readers may actually function as a bulwark against seduction."

Also basic skills like reading affect IPS in general and evaluation in particular. Rouet et al. (2011) for instance, found that reading skills are prerequisite for the acquisition of effective evaluation strategies (i.e., selecting sources based on reading semantic instead of superficial cues in SERPs; see also Mason, Boldrin, \& Ariasi, 2010, in press). Another interesting personal variable that affects IPS activity is personal epistemology (Hofer, 2001). Kienhues et al. (2011) focus on epistemic beliefs, a constituent of personal epistemology. Recent research on epistemic beliefs and IPS shows that advanced beliefs about the nature of knowledge (i.e., certainty and simplicity of knowledge) and the process of knowing (i.e., source of knowledge and justification for knowing) result in more efficient and effective IPS activity (Hofer, 2004; Mason et al., 2010, in press). Kienhues et al. (2011) found proof that the relationship between epistemic beliefs and Web-based information search is also the other way round. Participants in their study who dealt with conflicting information (in multiple Web-based documents) showed evidence of (more) advanced (topic-related) epistemic beliefs. These are interesting results since they support, to a certain extent, arguments for the use of Internet as an epistemological tool for learning (cf. Tsai, 2004).

\section{Methodological issues}

The (quasi) experimental designs described in the present section show rigor. However, we would like to address two methodological issues which according to our view jeopardize the findings of the studies, namely measurement of data and authenticity of experimental tasks.

Both Bråten et al. (2011) and Kienhues et al. (2011) used "paper-and-pencil" posttests to measure the dependent variables. Further, Kienhues et al. (2011) and Rouet et al. (2011) analyzed task processing "products" (e.g., decisions or selections). The focus on indirect measurement of evaluation behavior can be criticized. Most of the aforementioned researchers acknowledge that it would be good to capture the evaluation process in order to elicit explanations for information and source selection. Thinking-aloud, trace, and eye-tracking methods are mentioned explicitly. Gerjets et al. (2011) concurrently used thinking-aloud and eye-tracking as methods to capture information evaluation processes. Moreover, they compared two thinking-aloud versions, that is, a spontaneous version where individuals were just asked to perform a task and to think aloud, and an instructed version where individuals received instructions about the type of task (frequently used in information science studies). Gerjets et al. (2011) claim that the instructed version influences student behavior. Therefore, the results inferred from these studies should be looked at in its perspective. Gerjets et al. (2011) even question the standard thinking-aloud method, because this is "still not very close to a natural search situation." For capturing the evaluation processes of searchers, it would probably be wise to triangulate data and combine methods. An interesting suggestion put forward by Gerjets et al. (2011) is the cued-retrospective reporting method (see Van Gog et al., 2005).

The evaluation process eliciting methods are timeconsuming, especially when you want to capture evaluation processes of authentic (complex) IPS tasks. Complex IPS tasks that include solving ill-structured problems take time. In case of the vignette, a non-knowledgeable parent (in medicine) would probably take several hours to search, scan, and examine documents. Not imitating a true-to-life task situation in one's research method would probably lead up to biased results. Gerjets et al. (2011) acknowledged this pitfall. The participants in their study only had $20 \mathrm{~min}$ to evaluate a SERP and thirty documents. Time pressure most likely influenced evaluation behavior. As mentioned earlier in this commentary, the same authenticity problem came to light in Kienhues et al.'s (2011) study. Also Bråten et al. (2011) and Rouet et al. (2011) note some shortcomings regarding authenticity or fidelity in their research. The simulated SERPs used in Rouet et al.'s (2011) study were not prototypical and the way Bråten et al. (2011) presented the documents to the students doesn't match reality. As a future direction in IPS research we recommend to aim for research that addresses the problem of ecological validity more seriously.

\section{Instructional support}

Although the studies in this special section did not explicitly focus on instructional support for learning IPS (i.e., the evaluation skills in particular), some remarks on evaluation skill acquisition were put forward by the researchers. These remarks will be commented upon.

Probably most of us have acquired IPS evaluation skills "on the job". We learn to evaluate digital information by performing search tasks in educational settings, at work, and while performing search tasks for leisure. The success and failure of these endeavors shape our knowledge and skills regarding the evaluation of SERPs, sources, and information within sources. This discovery-based "learning-by-doing" approach might be complemented with goal-driven instructional activities (e.g., an on-line IPS course) or just-in-time 
instructional support (e.g., consulting a colleague). As the articles in the present special section show, advancing topic knowledge, procedural knowledge, and personal epistemology will also influence the effectiveness of information evaluation (and the search in general). Explicit support facilitates evaluation skill acquisition. Gerjets et al. (2011) found that encouraging learners to engage in quality-related evaluation processes helps learners to improve their Web search performance. Rouet et al. (2011) found that pre-search elaboration of content can have a positive effect on students' IPS activity. Although this effect was only significant for good readers, performing a preparatory task might be a good instructional strategy (cf. activating prior knowledge in the initial stages of IPS). More extensive information on instructional support for learning evaluation skills is provided by Bråten et al. (2011). They point to special educational tools (Stadtler \& Bromme, 2007) and units for learning evaluation skills (Graesser et al., 2007).

In educational settings where IPS is an integral part of the curriculum (e.g., resource-based learning curricula, or problem-based learning curricula) the issue of task complexity should be borne in mind. In the beginning of a curriculum learning tasks should be authentic, but relatively simple. At the end of a curriculum learning tasks should be authentic, but relatively complex (for a comprehensive view on instructional design for complex learning, see Van Merriënboer \& Kirschner, 2007). The IPS constituent of learning tasks should also follow this simple-to-complex sequence. When students in the beginning of a curriculum are asked to search for information to solve a problem, task complexity could be reduced by offering a predefined set of Web-based resources (cf. Segers \& Verhoeven, 2009). More advanced learning tasks at the end of the curriculum could include a full Web-based search with time constraints. For instance, when the vaccination problem presented in the vignette would be a learning task in a basic module in medical education (for aspirant general practitioners), students could be offered a predefined set of sources with conflicting information.

\section{Conclusion}

The four studies in the present special section contribute to an all-inclusive cognitive model of IPS activity. Previously unattached issues regarding evaluation, personal epistemology and research methodology were addressed in depth. The participating students in the special section's studies evaluated text-based information to solve their information problems. Since information on the Web is mainly text-based (or document-based; cf. Rouet, 2009) this focus is justifiable. However, it should be borne in mind that audio, video, and multimedia sources win ground on the Web and, as a result, are increasingly used for (personal) knowledge construction (Greenhow, Robelia, \& Hughes, 2009). Future research should consider the evolution of the Web towards a predominantly multimedia-based information source.

\section{References}

Brand-Gruwel, S., \& Gerjets, P. (Eds.). (2008). Instructional support for enhancing students' information problem solving ability. Computers in Human Behavior, 24(3). [Special issue].

Brand-Gruwel, S., Wopereis, I., \& Vermetten, Y. (2005). Information problem solving by experts and novices: analysis of a complex cognitive skill. Computers in Human Behavior, 21, 487-508.

Brand-Gruwel, S., Wopereis, I., \& Walraven, A. (2009). A descriptive model of information problem solving while using Internet. Computers \& Education, 53, 1207-1217.

Bråten, I., Strømsø, H. I., \& Salmerón, L. (2011). Trust and mistrust when students read multiple information sources about climate change. Learning and Instruction, 21(2), 180-192.

Eisenberg, M. B., \& Berkowitz, R. E. (1990). Information problem-solving: The big six skills approach to library and information skills instruction. Norwood, NJ: Ablex.

Gerjets, P., Kammerer, Y., \& Werner, B. (2011). Measuring spontaneous and instructed evaluation processes during Web search: integrating concurrent thinking-aloudprotocols and eye-tracking data. Learning and Instruction, 21(2), 220-231.

Graesser, A. C., Wiley, J., Goldman, S. R., O’Reilly, T., Jeon, M., \& McDaniel, B. (2007). SEEK Web tutor: fostering a critical stance while exploring the causes of volcanic eruption. Metacognition and Learning, 2, 89-105.

Greenhow, C., Robelia, B., \& Hughes, J. E. (2009). Learning, teaching, and scholarship in a digital age. Web 2.0 and classroom research: what path should we take now? Educational Researcher, 38, 246-259.

Hill, J. R. (1999). A conceptual framework for understanding information seeking in open-ended information services. Educational Technology, Research and Development, 47(1), 5-27.

Hill, J. R., \& Hannafin, M. J. (1997). Cognitive strategies and learning from the World Wide Web. Educational Technology, Research and Development, 45(4), 37-64.

Hilligoss, B., \& Rieh, S. Y. (2008). Developing a unifying framework of credibility assessment: construct, heuristics, and interaction in context. Information Processing and Management, 44, 1467-1484.

Hofer, B. K. (2001). Personal epistemology research: implications for learning and teaching. Journal of Educational Psychology Review, 13, 353-383.

Hofer, B. K. (2004). Epistemological understanding as a metacognitive process: thinking aloud during online searching. Educational Psychologist, 39, 43-55.

Kienhues, D., Stadtler, M., \& Bromme, R. (2011). Dealing with conflicting or consistent medical information on the Web: when expert information breeds laypersons' doubts about experts. Learning and Instruction, 21(2), 193-204.

Lazonder, A. W., \& Rouet, J.-F. (2008). Information problem solving instruction: some cognitive and metacognitive issues. Computers in Human Behavior, 24, 753-765.

Leiner, B. M., Cerf, V. G., Clark, D. D., Kahn, R. E., Kleinrock, L., Lynch, D. C., et al. (2009). A brief history of the Internet. ACM SIGCOMM Computer Communication Review, 39(5), 22-31.

Lemire, M., Paré, G., Sicotte, C., \& Harvey, C. (2008). Determinants of Internet use as a preferred source of information on personal health. International Journal of Medical Informatics, 77, 723-734.

Mason, L., Boldrin, A., \& Ariasi, N. (2010). Epistemic metacognition in context: evaluating and learning online information. Metacognition and Learning, 5, 67-90.

Mason, L., Boldrin, A., \& Ariasi, N. (in press). Searching the Web to learn about a controversial topic: are students epistemically active? Instructional Science.

Moore, P. (1995). Information problem solving: a wider view of library skills. Contemporary Educational Psychology, 20, 1-31.

Rouet, J.-F. (2009). Managing cognitive load during document-based learning. Learning and Instruction, 19, 445-450.

Rouet, J. -F., Ros, C., Goumi, A., Macedo-Rouet, M., \& Dinet, J. (2011). The influence of suface and deep cues on grade school students' assessment of relevance in Web menus. Learning and Instruction, 21(2), 205-219.

Segers, E., \& Verhoeven, L. (2009). Learning in a sheltered Internet environment: the use of WebQuests. Learning and Instruction, 19, 423-432. 
Stadtler, M., \& Bromme, R. (2007). Dealing with multiple documents on the WWW: the role of metacognition in the formation of documents models. Computer Supported Collaborative Learning, 2, 191-210.

Tsai, C.-C. (2004). Beyond cognitive and metacognitive tools: the use of the Internet as an 'epistemological' tool for instruction. British Journal of Educational Technology, 35, 525-536.
Van Gog, T., Paas, F., Van Merriënboer, J. J. G., \& Witte, P. (2005). Uncovering the problem solving process: cued retrospective reporting versus concurrent and retrospective reporting. Journal of Experimental Psychology: Applied, 11, 237-244.

Van Merriënboer, J. J. G., \& Kirschner, P. A. (2007). Ten steps to complex learning. Mahwah, NJ: Erlbaum. 